\title{
Desain Instrumen Smart System Berteknologi IoT dan Hybrid Power
}

\author{
Agus Putu Abiyasa ${ }^{1}$, I Kadek Arta Wiguna ${ }^{2}$, I Gusti Ayu Wulan Krisna Dewi ${ }^{3}$ \\ ${ }^{123}$ Program Studi Teknologi Informasi, Fakultas Teknik dan Informatika, Universitas Pendidikan Nasional
}

\begin{abstract}
Electrical energy is a primary need used in life. Electrical energy can be sourced from many things such as coal, oil, wind, nuclear and solar energy. Solar energy is one of the renewable energies where the utilization of solar energy in Indonesia is still not optimal even though solar energy in Indonesia is very abundant. In the use of electrical energy, they often experience problems with power outages and do not have a backup energy source so that it hampers human activities, especially in the field of hydroponic agriculture. Hydroponic farming relies heavily on electrical energy to power devices such as pumps and blowers. Therefore this study discusses a hybrid power system with IoT technology which is designed according to industry standards with literacy search methods, design and planning, etching and soldering and testing. The purpose of this research is to create a tool that is capable of hybrid power between PLN electricity with solar electricity, in order to help farmers in the field of hydroponics. The results of this research are the design of smart system instruments with IoT technology and hybrid power.
\end{abstract}

Keywords: Hybrid Power and IoT Technology

\begin{abstract}
ABSTRAK
Energi listrik merupakan kebutuhan primer yang digunakan dalam kehidupan. Energi listrik dapa bersrumber dari banyak hal seperti energi batu bara, minyak, angin, nuklir serta energi matahari. Energi matahari merupakan salah satu energi terbarukan yang dimana pemanfaatan enargi matahari di Indonesia masih belum optimal padahal energi matahari di Indonesia sangatlah melimpah. Dalam penggunaan energi listri sering kali mengalami permasalahan padamnya energi listrik dan tidak memiliki sumber energi cadanganan sehingga menghambat kegiatan manusia khususnya dibidang pertanian hidroponik. Pertanian hidroponik sangan bergantung pada energi listrik untuk menyakan perangkat seperti pompa dan blower. Maka dari itu penelitian ini membahas tentang sistem hybrid power yang berteknologi IoT yang dirancang sesuai sandar industri dengan metode pencarian literasi, perancangan serta perencanaan, etching dan soldering serta pengujian. Tujuan dari penelitian ini adalah untuk menciptakan sebuah alat yang berkemampuan hybrid power antara energi listrik PLN dengan Energi listrik matahari, agar bisa membantu petani di bidang hydroponik. Hasil dari penelitian ini berupa design instrumen smart system berteknologi IoT dan hybrid power.
\end{abstract}

Kata kunci: Hybrid power dan Teknologi IoT

Info Artikel

Diterima Redaksi : 01-11-2021

This is an open access article under the CC BY-SA license.

Selesai Revisi

Diterbitkan Online $\quad$ : 30-12-2012

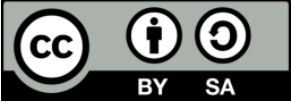

Penulis Korespondensi:

Agus Putu Abiyasa

Program Studi Teknologi Informasi,

Universitas Pendidikan Nasional,

Mengwi, Badung.

Email: abiyasa@undiknas.ac.id

\section{PENDAHULUAN}

Energi listrik merupakan kebutuhan dasar untuk kehidupan manusia hal ini lebih disebabkan oleh pesatnya peningkatan populasi dunia, teknologi dan kondisi politik dan ekonomi lainnya. Sekarang energi listrik sehari dihasilkan oleh sumber daya energi konvensional seperti batu bara, solar, dan nuklir dan lain sebgainya hal ini semakin menipis dari hari ke hari. Jadi, ada kebutuhan mendesak untuk beralih ke sumber daya energi non- konvensional. Matahari yang mudah didapat dalam segala kondisi dapat menjadi sumber 
alternatif yang baik. Dengan meningkatnya permintaan sumber daya energi terbarukan, kebutuhan pemanfaatan yang lebih baik dari sistem ini telah muncul[1]. Baru baru ini telah munculsystem energi listrik hibrida. Hybrid Energy System adalah kombinasi dari dua atau lebih sistem energi. Di sini, dua sumber digunakan energi matahari dan energi listrik dariPLN[2]. Pada da sarnya IoT adalah penghubungan komponen komponen yang mendapatkan da ta kemudian di simpan di da tabase yang berbasis cloud computing[3]. Namun komponen komponen IoT memerlukan sumberdaya listrik untuk melakukan tugasnya masing-masing. Permasalahan yang sering terjadi dalam penggunaan IoT adalah bergantung pada listrik PLN untuk sumberdayanya sehingga dampak yang terjadi adalah ketika PLN mengalami permasalahan sehingga melakukan pemadaman listrik dalam waktu yang cukup lama, maka perangkat IoT tidak bisa bekerja secara efektif[4]. Selain itu dalam dunia industry, ketika menggunakan sumberdaya listrik tidak terekam dalam system manajemen perusahaan, ka rena satu sumber listrik digunakan tidak efektif kare na yang seharusnya tidak perlu menyala terus menerus, dinyalakan terus karena dikontrol oleh tenaga manusia. Sehingga penggunaan sumberdaya listrik bisa dibilang boros[5].

Pada penelitian lain telah menerapkan system energy hybrid, dimana penelitian tersebut menggunakan energy matahari yang dimuat dalam bentuk panel surya sebagai energy utama (energy prioritas) dan energy dari PLN sebagai energy cadangan. Penelitian tersebut menerapkan system hybrid untuk menyalakan pompa air rumahan agar tetap menyala dan hemat biaya[6] penelitian lain juga melakukan hal serupa namun dipergunakan di areal parker mobil[7].

Berdasarkan latarbelakang masalah diatas dan merujuk pada penelitian yang sudah ada peneliti ini berfokus pada desain kontrol power energy listrik berbasis IoT dengan menggunakan metode hybrid power yang dipasangkan pertanian hydroponic yang berbasis teknologi. Penelitian ini menggunakan listrik PLN sebagai sumber energy hidup di malam hari dan sumber energy matahari sebagai energy akan hidup disiang hari. Sehinga perangkat perangkat pertanian hydoponik da pat berfungsi dengan baik.

\section{METODE PENELITIAN}

Pada penelitian ini telah melalui beberapa tahapan tahapan yaitu proses pencarian literasi, Tahap Perencanaan beserta perancangan, Tahap Instalasi dah tahapan ujicoba .

\subsection{Tahapan Pencarian Literasi}

Tahapanan awal dari penelitian ini adalah tahapan pencarian literasi sebagai pendukung untuk pembuatan alat ini. Ada penelitian yang menggunakan sistem pembangkit listrik catu daya dengan sistem refrigerasi dalam penelitian tersebut menyebutkan bahawa sumber energi mataharidi indonesia sangatlah melimpah namun pemanfaatan dari energi matahari masih kurang dimanfaatkan. Tujuan dari penelitian tersebut adalah untuk mengkasi kelayakan penggunaan energi matahari khususnya di indonesia. Dari penelitian tersebut memperoleh hasil yaitu sistem panel surya dapat digunakan untuk mengisi baterai dengan energi 396Wh dengan estima si waktu kurang lebih 4 jam, sehingga dapat menjalankan mesin refrigera si dengan daya $120 \mathrm{~W}$ selama 3 jam secara terus menerus [8].

Penelitian lainnya juga menerapkan hibrida teknologi untuk catu daya Penyimpanan energi listrik Fotovoltaik surya (PV-EES). Sistem PV-EES hibrida adalah teknologiyang menjanjikan untuk memfasilitasi re-penetrasi energi terbarukan dan mencapai kemandirian energi bangunandengan pasar aplikasi yang berkembang pesat. Kajian ini memberikan gambaran tentangperkembangan terbaru dari sistem PV-EES hybrid untuk catu daya untukbangunan dalam hal status aplikasi global serta re-kemajuan pencarian pada kinerja sistem dan optimasi desain.Temuan berikut dan kesenjangan penelitian diidentifikasi untuk mempromosikan penerapan teknologi PV-EES pada bangunan. Teknologi PV-EES hibrida yang ditujukan untuk membangun catu daya memilikipersyaratan khusu s pada kondisi aplikasi seperti geografi, cuaca, skala penyimpanan dan beban bangunan. Disaranka nuntuk secara komprehensif mempertimbangkan kondisi lokal dari sisi sumber, sisi permintaan dan sisi grid ketika menyelidiki teknis, eko-kelayakan ekonomi dan lingkungan. Optimalisasi sistem PV-EES hybrid dapat dilakukan lebih lanjutuntuk mendapatkan ketahanan dan kecerdasan bangunan yang lebih tinggi, mengingatperilaku manusia dan kenyamanan termal dari berbagai fungsionalruang untuk memenuhi preferensi penghuni dalam konteks perkota an [9].

Penelitian lain juga menjelaskan tentang penyimpananhybrid dipompa baterai(HPBS) untuk RES di luar jaringan. Model matema tis untuk setiap komponen sistem adalahdikembangkan dan strategi opera si banu berdasarkan penyimpanan hybrid adalahdiperkenalkan. Pertama, sumber daya matahari dan angin yang tersedia untuk remotepulau dievaluasi, dan kemudian ukuran PV, turbin angin, dan penyimpanansistem 
disajikan. Selain itu, strategi operasi HPBS ditentukandikembangkan yang jarang dieksplorasi dalam studi yang ada. Rentang operasi:setiap penyimpanan energi sangat penting untuk penyimpanan hybrid yang tepatfungsiona litas yang didefinisikan da lam penelitian ini setelah beberapa simula sika sus, untuk mengekstrak energi tersimpan maksimum menjaga efisiensi HPBS tetapwaktu. Selain itu, output daya dari setiap penyimpanan dan lengkapaliran energi sistem disimulasikan sehubungan dengan permintaan beban.Mempertimbangkan kendala keandalan 100\%, kinerja HPBS adalahdievaluasi menggunakan kinerja penyimpanan keseluruhan (SOP) dan penggunaan penyimpananparameter faktor (SUF).Analisis keluaran energi terperinci mengungkapkan bahwa selama da ya tinggiperiode waktu kekurangan, PHS mulai beroperasi melihat minimumKendala SOC, sementara kekurangan yang rendah ditutupi oleh bank baterai.PHS dan bank baterai tetap beroperasi selama 15,5 jam dan 12,6 jamper hari (rata-rata), masing-masing. Hasilnya mengungkapkan bahwa dengan pengaturan hidrooperasi turbin dalam kisaran dari $20 \%$ hingga $100 \%$, PHS memiliki SUF. yang tinggi30\% (rata-rata tahunan) sedangkan bank baterai memiliki SOP tinggi 95\%, karenauntuk kekurangan energi yang sering terja di. Keseluruhan SUF dan SOP HPBS adalah7,3\% dan 66,4\%, masing-masing. Seluruh sistem EUR adalah 16,5\%. Diamenyimpulkan bahwa HPBS dapat secara efektif mengelola variasi energi dantampaknya merupakan aspek yang menjanjikan, terutama untuk sistem ET offgrid, seperti PHS danpenyimpanan baterai memiliki karakteristik yang saling melengkapi, selain saling melengkapi selama periode pengisian daya rendah.Penyimpanan hybrid adalah konsep yang popule $r$ saat ini. Setelah memulai denganstrategi operasi teknis yang kuat dari HPBS berdasarkan operasirentang setiap penyimpanan energi, langkah selanjutnya a dalah menganalisis HPBS dengan melakukan analisis sensitivitas dalam kondisi yang berbeda yaitu memvariasikanmemuat dan ukuran penyimpanan, memvariasikan saturasi genera tor RE dan untuk memva lida siitu melalui eksperimen [10].

\subsection{Tahapan Perencanaan Dan Perancangan}

Tahapan perenca naan meliputi perenca naan hardware dan perencanaan software yang akan digunakan, dalam pembuatan sistem hybrid power menggunakan software EAGLE untuk Designnya dengan design seperti berikut.

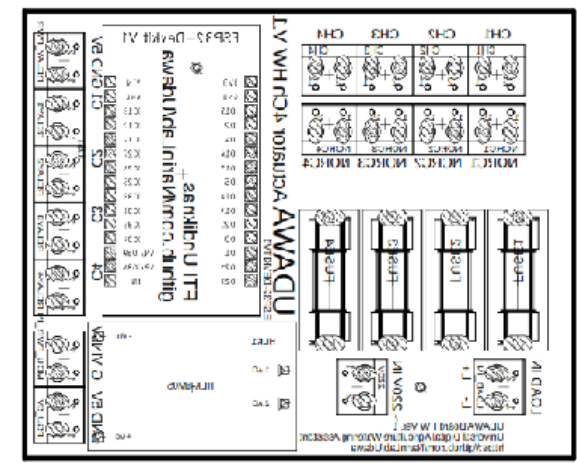

Gambar 1. Rancangan Pembuatan system hybrid power.

Dalam system hybrid power dimana diperlukan beberapa skematik untuk terminal220V (2 block x 1) untuk inputan listik dari PLN, terminal AC/DC (2 block x 1) untuk inputan listrik dari energi surya, terminal control relay (Cx + VCC + GND) (2 block x 3) sebagai pengaturan alur listrik, fuse holder (4 unit), seba gai perangkat kea manan a pabila menga lami perma salahan pada a liran arus kuat akan menghanguskan fuse holder, sehingga tidak merusak komponen pada arus lemah, terminalblock $\sim \mathrm{RCx}$ (2 block x 2) dan terminal block NOx (2 block x 2) untuk menghubungkan ke relay serta terminal block stop kontak CHx (2 block x 4) untuk stop kontak yang akan dihubungkan ke instrument hydroponik seperti blower, misting dan pompa .

Perlengkapan hardware yang digunakan untuk membuat system hybrid power adalah screw terminal, fuse holder, Relay, Esp32, PCB Polos dan kabel secukupnya. Pada perlengkapan hardware ini dirancang dalam waktu 2 minggu.

\subsection{Tahapan Etching dan Soldering}

Tahapan ini merupakan tahapan perakitan komponen komponen dalam perancangan ke dalam PCB agarbisa terhubung satu sama lain. 


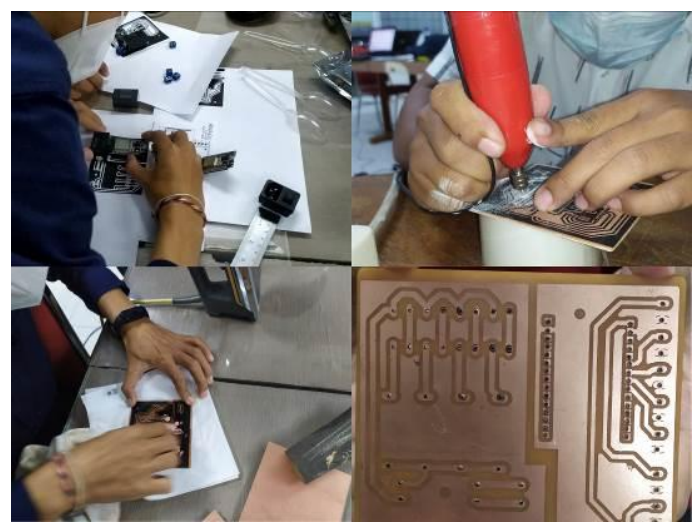

Gambar 2. Proses instalasi komponen hybrid power

Dalam proses Etching dan Soldering yang perlu diperhatikan adalah proses etching dimana dalam proses ini menggunakan larutan HCL h2o o2 dimana larutan tersebut merupakan air keras yang melarutkan tembaga, sebelum proses etching ada satu proses yang dilalui yaitu proses cetak design pc di transfer paper menggunakan printer toner kemudian ditempel di PCB polos dan distrika hingga tinta menempel pada PCB, setelah tinta menempel pada PCB maka dilakukan proses etching agar tembaga yang tidak ditutupi tinta bisa larut. Kemudian bersihkan PCB dan lanjutkan ke proses berikutnya. Proses berikutnya adalah proses pelubangan PCB dengan menggukan bor PCB, kemudian komponen komponen dipasangkan ke PCB sesuai design dan disolder dengan timah. Dalam tahapan ini dipastikan tidak ada loss agar tidak terjadierorr.

\subsection{Tahapan Pengujian}

Pada tahapan uji coba dilakukan dengan dua cara yaitu uji coba keamanan di laborataorium TI Undiknas dan ujicoba lapangan pada Prita Lab Undiknas. Dalam tahapan ini perlu di perhatikan ketika menggunakan listrik PLN (220V) perlu dilakukan Jumper menggunakan kabelJumper pada inputan terminal AC/DC, begitu pula pada saat menggunakan energi listrik mataharidiperlukan jumper pada inputan term inal 220V. Pengujian dilakukan dengan menggunakan multi tester sehingga terjadinya konselting listrik tidak terjadi serta pengujian dilakukan dengan cara pengecekan jalur jalur pada board sehingga tidak terputus yang seharusnya terhubung. System hybrid power ini telah dilengkapi dengan sistem kea manan melaluifuse holder yang dimana berfungsi ketika a da erorr di tegangan tinggi $(220 \mathrm{~V})$ maka fuse ini yang akan meledak dan tidak akan merusak board. Proses ujicoba di Laboratorium TI Undinas dilakukan untuk menguji a liran harus listrik menggunkan tester, sedangkan uji coba di Prita Lab Undiknas dilakukan untuk mengetahui kekurangan perangkat agar bisa diperbaiki sebelum di implementasikan. Pengujian juga dilakukan di lapangan pada GAURI, Penebel Tabanan, Bali untuk mengetahui ketika disambungkan pada energi panel surya dan setelah dilakukan ujicoba, sudah bisa berjalan dengan baik.

\section{HASIL DAN PEMBAHASAN}

Dari metode tahapan yang sudah tertera diatas terdapat hasil penelitian ini, setelah mendapatkan literasi kemudian dikaji dan mendapatkan ide untuk membuat system hybrid power yang diterapakan pada pertanian hydroponik yang berguna untuk memberikan energi listrik pada instrumen-insstrumen pertanian hydroponik, sehingga perangkat perangkatnya tidak terputus listriknya ketika a da pemadaman dari listrik PLN.

Hasil dari penelitian ini adalah sebuah aktuator yang memiliki kemampuan hybrid power. Sistem hybrid power ditanamkan pada instrumen aktuator sehingga ketika listrik PLN padam maka listrik dari energi surya bisa di pergunakan dengan memasangkan kabel jamper pada inputan listrik PLN. 


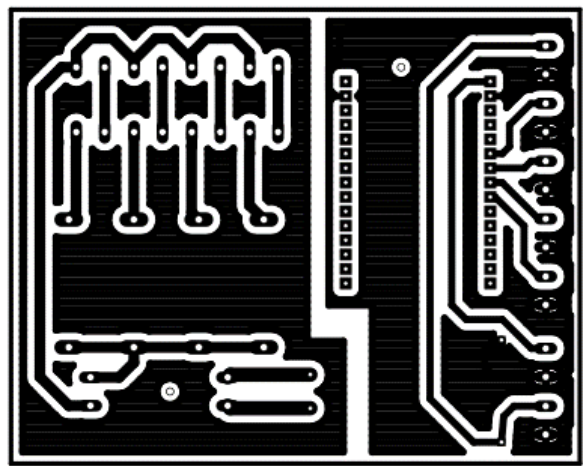

Gambar 3. Design Instrumen Aktuator berkemampuan hybrid power

Design aktuator menggunakan tools Eagle dengan menerapkan standar design PCB maka terbentuklah design seperti diatas, yang sudah mematuhi aturan pembuatan PCB. Design aktuator tersebut dirancang sesuai dengan pasaran industripada umumnya sehingga bisa dibilang layak untuk di pasarkan ke dunia industri.

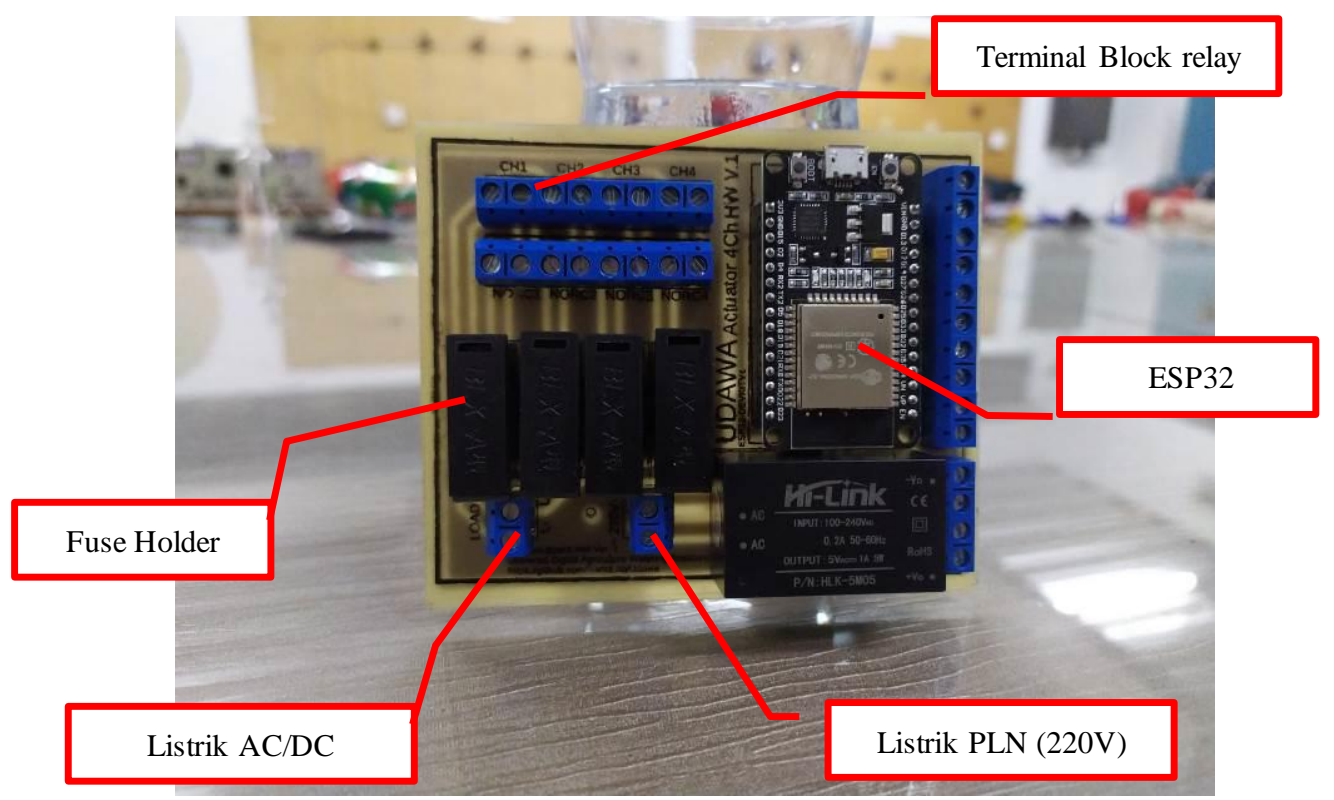

Gambar 4. Board Aktuator berkemampuan hybrid power

Pada gambar 6 merupakan board aktuator yang dirancang berkemampuan hybrid power. Board aktuator ini memiliki komponen pengamanan yang menggunakan fuse holder yang dimana ketika ada konsleting arus listrik board tidak akan terbakar karena yang terbakar adalah fuse holder sehingga akan mematikan arus listrik ke board. Komponen lainnya adalah relay $4 \mathrm{ch}$ yang berfungsi untuk mengatur arus listrik ke perangkkat hydroponik

\section{KESIMPULAN}

Sistem hybrid power merupakan sistem manajemen dua atau lebih arus listrik. Sistem hybrid power dirancang untuk membuatkan listrik cadangan yang dimana ketika listrik uta ma pada maka bisa memanfaatkan sumber energi cadangan seperti energi matahari. Penelitian ini membahas tentang sistem hybrid power yang ditanamkan pada board aktuator sehingga board aktuator bisa bekerja dengan baik karena mempunyai listrik cadangan ketika listrik utama padam. Dari penelitian ini masih banyak yang bisa dikembangakan sehingga peneliti masih terus menkaji teknologi teknologi terbarukan dan peneliti masih memerlukan kritik dan saran dari peneliti peneliti lainnya.

\section{UCAPAN TERIMAKASIH}


Dalam penelitian ini mendapatkan banyak support dari dosen dosen beserta rekan rekan mahasiswa di Fakultas Teknik dan Informatika Universitas Pendidikan Nasional, khusunya bapak I Wayan Aditya Suranata, S.Kom., M.Kom yang selalu membimbing dan membina sehingga project ini bisa rampung tepat waktu. Tak luput juga saya mengucapkan terimakasih terhadap rekan rekan di KP TI Bach I yang selalu memberikan semangat dan ikut serta dalam project ini.

\section{DAFTAR RUJUKAN}

[1] P. Srivastava, M. Bajaj, and A. S. Rana, "IOT based controlling of hybrid energy system using ESP8266," 2018 IEEMA Eng. Infin. Conf. eTechNxT 2018, pp. 1-5, 2018, doi: 10.1109/ETECHNXT.2018.8385294.

[2] K. Sureshkumar and V. Ponnusamy, "Hybrid renewable energy systems for power flow management in smart grid using an efficient hybrid technique,” Trans. Inst. Meas. Control, vol. 42, no. 11, pp. 2068-2087, 2020, doi: 10.1177/0142331220904818.

[3] S. Tang, L. Chen, K. H. Xia, L. Fan, and A. Nallanathan, "Computational Intelligence and Deep Learning for Next-Generation Edge-Enabled Industrial IoT,”pp. 1-11, 2021, [Online]. Available: http://arxiv.org/abs/2110.14937.

[4] M. B. Rizki, P. Pangaribuan, and A. Suhendi, "Desain dan Implementasi Smart Switching Pada Sistem Catu Saya Listrik On Grid,” $e$ - Proceeding Eng., vol. 6, no. 2, pp. 2649-2656, 2019, [Online]. Available: https://openlibrary.telkomuniversity.ac.id/pustaka/files/152436/jurnal_eproc/desain-dan-implementasi-smartswitching-pada-sistem-catu-daya-listrik-on-grid.pdf.

[5] Y. Adekayanti, I. Adiasa, and I. Mashabai, "Analisis Gangguan Pada Kwh Meter Pelanggan Di Pt. Pln ( Persero ) Up3 Sumbawa Menggunakan Fishbone Dan Pdca ( Plan , Do, Check, Action )," vol. 2, no. 1, 2021.

[6] A. B. Pulungan, J. Sardi, and J. T. Elektro, "Pemasangan Sistem Hybrid Sebagai Penggerak Pompa Air," JTEV (Jurnal Tek. Elektro dan Vokasional), vol. 5, no. 2, p. 2019, 2019, [Online]. Available: http://ejournal.unp.ac.id/index.php/jtev/indexJTEV.

[7] E. Timotius, A. Duka, N. Setiawan, and A. I. Weking, "Eric Timotius Abit Duka, I Nyoman Setiawan," Antonius Ibi Weking, vol. 5, no. 2, p. 67, 2018.

[8] A. Setyawan, T. Sutandi, and M. Markus, "Desain Sistem Pembangkit Listrik Tenaga Surya Off-Grid untuk Catu Daya Sistem Refrigerasi,” ReTII, vol. 2018, no. November, pp. 362-368, 2018, [Online]. Available: https://journal.itny.ac.id/index.php/ReTII/article/view/938.

[9] J. Liu, X. Chen, S. Cao, and H. Yang, "Overview on hybrid solar photovoltaic-electrical energy storage technologies for power supply to buildings," Energy Convers. Manag., vol. 187, no. February, pp. 103-121, 2019, doi: 10.1016/j.enconman.2019.02.080.

[10] M. S. Javed, D. Zhong, T. Ma, A. Song, and S. Ahmed, "Hybrid pumped hydro and battery storage for renewable energy based power supply system," Appl. Energy, vol. 257, no. October 2019, p. 114026, 2020, doi: 10.1016/j.apenergy.2019.114026. 